\title{
Comparison of bromide and nitrate transport in the Bainsvlei soil of South Africa under natural rainfall
}

\author{
Ketema Tilahun ${ }^{1 *}$, Joseph F Botha ${ }^{1}$ and Alan TP Bennie ${ }^{2}$ \\ ${ }^{1}$ Institute for Groundwater Studies, University of the Free State, PO Box 339, Bloemfontein 9300, South Africa \\ ${ }^{2}$ Department of Soil, Crop, and Climate Sciences, University of the Free State, PO Box 339, Bloemfontein 9300, South Africa
}

\begin{abstract}
Bromide is commonly used to simulate the movement of nitrate fertilisers through the soil profile. However, there exists no comparative evaluation of the leaching properties of $\mathrm{Br}^{-}$and $\mathrm{NO}_{3}^{-}-\mathrm{N}$ under local soil and rainfall conditions at Bloemfontein. The purpose of this work was to conduct a field experiment to evaluate the leaching behaviour of $\mathrm{Br}$ in comparison with $\mathrm{NO}_{3}^{-}-\mathrm{N}$ on the Bainsvlei soil of South Africa under natural rainfall conditions. For this purpose, $\mathrm{KBr}$ and $\mathrm{KNO}_{3}$ solutions were applied to a $2.45 \times 2.45 \mathrm{~m}^{2}$ plot at rates of $13.5 \mathrm{~g} \mathrm{Br} \cdot \mathrm{m}^{-2}$ and $20 \mathrm{~g} \mathrm{~N} \cdot \mathrm{m}^{-2}$ respectively. The subsequent movement of the solutes through the soil was investigated through studies of the water and mass balances, determined from soil samples taken from a $1600 \mathrm{~mm}$ deep soil profile during the period October 2000 to May 2001, the rainy season in Bloemfontein. The results were also analysed with the one-dimensional convective dispersive equation and stream tube models. Two important results were derived from the study: $\mathrm{Br}$ can be used with confidence as a substitute for $\mathrm{NO}_{3}^{-}-\mathrm{N}$ in studies of the movement of the latter through soils, and it is more economical and environmentally friendly to distribute the application of nitrate over the growing season of a crop, instead of applying it as a batch at the time of planting.
\end{abstract}

Keywords: Field observations, bromide, nitrate, transport

\section{Introduction}

In most instances, the leaching of nitrate is the single largest cause of nitrogen loss from the soil-plant system (Cameron and Haynes, 1986). Nitrate leaching from agricultural soils represents an economic loss to the farmer and a pollutant to groundwater resources. Since nitrogen experiences complex biochemical transformations in the soil-plant system, it is often difficult to determine the fate and movement of $\mathrm{NO}_{3}^{-}-\mathrm{N}$ through the soil profile. Isotopically labelled fertiliser (using ${ }^{15} \mathrm{~N}$ ) can be used to distinguish between fertiliser $\mathrm{N}$ and $\mathrm{N}$ from other sources with a high degree of accuracy. However, the use of these techniques is very costly (Silvertooth et al., 1992). Anions that are biologically and chemically conserved and similarly charged, with low background concentrations in the field, such as $\mathrm{Cl}^{-}$and $\mathrm{Br}$, are therefore often used to simulate the movement of $\mathrm{NO}_{3}^{-}-\mathrm{N}$ through natural soil profiles. Since bromide usually has very low background concentrations in the field and bears no known adverse effects to human health, provided it is applied in small quantities (Flury and Papritz, 1993), bromide is usually preferred in such studies (Nachabe et al., 1999; Silvertooth et al., 1992; Jardin et al., 1990; Jaynes et al., 1988; Rice et al., 1986; Smith and Davis, 1974).

The nitrate leaching behaviour of Bainsvlei soil of South Africa, which represents most of the South African land mass (Soil Classification Working Group, 1991), has not been studied before. The purpose of this investigation was to evaluate the leaching behaviour of $\mathrm{Br}^{-}$in comparison with $\mathrm{NO}_{3}^{-}-\mathrm{N}$ in this soil under natural conditions through a field experiment at the experimental

\footnotetext{
* To whom all correspondence should be addressed. Address for correspondence: Alemaya University, PO Box 138, Dire Dawa, Ethiopia 용 +251-5-111399; fax: +251-5-114008;

e-mail: ketematilahun@yahoo.com

Received 5 February 2003; accepted in revised form 27 July 2003.
}

station of the Department of Soil, Crop, and Climate Sciences of the University of the Free State, South Africa, from October 2000 to May 2001, the rainy season of the region. The computer package CXTFIT of Toride et al. (1995) was used to determine solute transport parameters with cumulative drainage (instead of time) as independent variable and to compare the movement of $\mathrm{Br}^{-}$and $\mathrm{NO}_{3}^{-}-\mathrm{N}$ in the soil.

\section{Materials and methods}

\section{Field experiment and laboratory analysis}

The experimental site, located at $26.1^{\circ} \mathrm{S}$ and $29.0^{\circ} \mathrm{E}$ with an altitude of $1372 \mathrm{~m}$, is underlain by a cultivated Bainsvlei Amalia sandy loam soil. It is characterised by orthic topsoil and red apedal/soft plinthic subsoil. The area is semi-arid with a mean annual rainfall of $510 \mathrm{~mm}$.

A square plot $\left(2.45 \times 2.45 \mathrm{~m}^{2}\right)$ of bare soil was prepared for the experiment. The plot was kept bare and weed-free throughout the experiment. The plot was levelled to prevent runoff and erosion from one part of the plot to another and isolated from the surrounding area by a sheet of galvanised iron to prevent surface and shallow subsurface flows into and out of the plot. The sheet of iron was driven into the soil to a depth of $200 \mathrm{~mm}$, with a $200 \mathrm{~mm}$ section protruding above ground level.

An access tube for a neutron probe was installed at the centre of the plot to a depth of $2000 \mathrm{~mm}$ to determine the soil water content at various depths. Rainfall was measured with two rain gauges near the experimental plot.

A water sample was taken from a borehole used at the experimental farm to determine the $\mathrm{NO}_{3}^{-}-\mathrm{N}$ concentration of the groundwater. The soil was analysed for its textural properties. The results of the soil particle analysis, the textural group and bulk densities of each soil layer are presented in Table 1. 
TABLE 1

Particle size distribution and bulk density of the soil profile

\begin{tabular}{|c|c|c|c|c|c|c|c|c|}
\hline \multirow{2}{*}{$\begin{array}{l}\text { Soil depth } \\
\qquad(\mathrm{mm})\end{array}$} & \multicolumn{4}{|c|}{ Sand $(\%)$} & \multirow{2}{*}{$\begin{array}{l}\text { Silt } \\
(\%)\end{array}$} & \multirow{2}{*}{$\begin{array}{l}\text { Clay } \\
(\%)\end{array}$} & \multirow{2}{*}{$\begin{array}{c}\text { Soil } \\
\text { texture }\end{array}$} & \multirow{2}{*}{$\begin{array}{l}\text { Bulk density } \\
\qquad\left(\mathrm{g}^{\cdot} \mathrm{cm}^{-3}\right)^{\star}\end{array}$} \\
\hline & Coarse & Medium & Fine & Total & & & & \\
\hline $0-200$ & 0.4 & 6.8 & 83.8 & 91 & 4 & 5 & Sand & $1.64 \pm 0.05$ \\
\hline $200-400$ & 0.4 & 7.7 & 78.9 & 87 & 2 & 11 & Loamy sand & $1.72 \pm 0.07$ \\
\hline $400-600$ & 0.3 & 5.5 & 70.2 & 76 & 6 & 20 & Sandy loam & $1.62 \pm 0.04$ \\
\hline $600-800$ & 0.4 & 5.5 & 72.1 & 78 & 6 & 18 & Sandy loam & $1.58 \pm 0.05$ \\
\hline $800-1000$ & 0.2 & 4.8 & 73.0 & 78 & 4 & 20 & Sandy loam & $1.64 \pm 0.06$ \\
\hline $1000-1200$ & 0.3 & 4.8 & 73.9 & 79 & 4 & 18 & Sandy loam & $1.67 \pm 0.08$ \\
\hline $1200-1400$ & 0.3 & 5.4 & 71.3 & 77 & 4 & 20 & Sandy loam & $1.68 \pm 0.08$ \\
\hline $1400-1600$ & 0.2 & 2.8 & 73.0 & 76 & 4 & 20 & Sandy loam & $1.71 \pm 0.04$ \\
\hline
\end{tabular}

At the beginning of the experiment, $\mathrm{KBr}$ and $\mathrm{KNO}_{3}$ were applied at intensities of $200 \mathrm{~kg} \mathrm{KBr} \cdot \mathrm{ha}^{-1}\left(13.5 \mathrm{~g} \mathrm{Br}^{-2} \mathrm{~m}^{-2}\right)$ and 1450 $\mathrm{kg} \mathrm{KNO}_{3} \cdot \mathrm{ha}^{-1}\left(20 \mathrm{~g} \mathrm{~N} \cdot \mathrm{m}^{-2}\right.$ or $\left.200 \mathrm{~kg} \mathrm{~N} \cdot \mathrm{m}^{-2}\right)$. Similar rates for $\mathrm{Br}$ have been used in other studies (Nachabe et al., 1999; Bicki and Guo, 1991; Owens et al., 1985; Baker and Laftlen, 1982), while the $\mathrm{KNO}$, intensity was chosen to use the $\mathrm{N}$ application rate commonly used by the farmers in the area. To make the solute application easier, the plot was divided into 6 subplots each with an area of $1 \mathrm{~m}^{2}$. For each subplot $20 \mathrm{~g} \mathrm{KBr}$ and $145 \mathrm{~g} \mathrm{KNO}_{3}$ were mixed in $500 \mathrm{~m} \ell$ distilled deionised water. The solution was applied uniformly with a hand held sprayer on 13 October 2000.

Soil samples were taken five times during the season using an auger type coring tube $200 \mathrm{~mm}$ long and $42 \mathrm{~mm}$ in diameter. The samples were taken from two locations at depth intervals of $200 \mathrm{~mm}$ from $0 \mathrm{~mm}$ to $1600 \mathrm{~mm}$. The core sampler was cleaned with tap water and rinsed with distilled water before reinsertion for the next depth of sampling. The plot was accessed through wooden planks put on concrete blocks around the plot to avoid soil disturbance and compaction. The resultant holes were all backfilled with soil from outside the plot immediately after retrieval of the cores.

Two samples taken from the same depths were mixed and a subsample of each was put in paper bags to determine its water content. The rest of the soil sample was sealed in polyethylene bags for $\mathrm{Br}$ and $\mathrm{NO}_{3}-\mathrm{N}$ analysis. The soil water content analysis was done gravimetrically by drying about $100 \mathrm{~g}$ of soil for $24 \mathrm{~h}$ at $105^{\circ} \mathrm{C}$.

The soil samples for $\mathrm{Br}$ and $\mathrm{NO}_{3}-\mathrm{N}$ analysis were oven dried and ground to pass a $2 \mathrm{~mm}$ sieve. A sample of $50 \mathrm{~g}$ of the dried soil was then mixed with $50 \mathrm{ml}$ of distilled deionised water (1:1 ratio) and the mixture shaken for one hour with a laboratory shaker. The solution was filtrated and the filtrates stored in a refrigerator at $4{ }^{\circ} \mathrm{C}$ until the $\mathrm{Br}$ and $\mathrm{NO}_{3}-\mathrm{N}$ concentrations were determined by ion chromatography (Dionex 2200I, Dionex Corp., Sunnyvale, CA) at the Institute for Groundwater Studies of the University of the Free State, South Africa. The $\mathrm{Br}$ and $\mathrm{NO}_{3}-\mathrm{N}$ concentrations in the soil were calculated from the filtrate concentration based on the mass of soil and volume of water used for extracting the filtrate and the gravimetric water content of the soil sample.

\section{Data analysis}

Rainfall, evaporation, deep percolation, and change in water content of the soil profile constitute the major components of water balance for the experimental plot. Of particular interest to this study is the deep percolation, $D_{p}$, the quantity of water that percolated below the potential rooting depth of plants, equated here with the sampling depth (1 $600 \mathrm{~mm}$ ), over a given period. This quantity is defined as:

$$
D_{p}=R-E_{v}-\Delta S
$$

where:

$$
\begin{aligned}
& R=\text { the rainfall, } \\
& E_{y}=\text { evaporation, } \\
& \Delta S=\text { change in storage over the given period. }
\end{aligned}
$$

The change in storage, $\Delta S$, was calculated from the water contents measured with the neutron probe. Evaporation from the bare soil has been determined using the equation of Ritchie (1972):

$$
E_{v}=C t^{v_{2}}
$$

where:

$$
t=\text { is the time. }
$$

The applicability of this equation in the study area has been investigated by Bennie et al. (1998). The results of this study indicated that $E_{v}$ is limited more by soil properties than climatic factors and that the coefficient, $C$, can be expressed as

$$
C=26.35\left(\theta_{i}-\theta_{a}\right)
$$

where:

$$
\theta_{i} \text { and } \theta_{a} \text { are the initial and air-dry volumetric water contents of }
$$
the topsoil respectively.

The mass balance of the applied solute was checked by computing the mass recovered from the core samples as:

$$
m_{i, j}=c\left(z_{i}, t_{j}\right) \theta\left(z_{i}, t_{j}\right) A \Delta z_{i}
$$

where:

$c(z, t)=$ the solute concentration,

$\theta\left(z_{i}, t\right)=$ volumetric soil water content at depth $z_{j}$ and sampling time $t_{\rho}$

$A=$ cross-sectional area of the core sampler, and

$\Delta z_{i} \quad=$ thickness of the sample $(200 \mathrm{~mm})$.

The total mass, $m_{\downarrow}$, of solute recovered from the soil profile over a depth $Z$ at a given horizontal position $\left(x_{k}, y_{k}\right)$ is then simply the sum of the $m_{i j}$ at $\left(x_{k}, y_{k}\right)$ :

$$
m_{k}=\sum_{i} m_{i j} \quad\left(z_{i} \leq Z\right)
$$

The average downward motion of a solute front is theoretically determined by the average seepage velocity of the water: 


$$
v_{w}=q / \theta
$$

where:

$q=$ the Darcian flux, and

$\theta=$ the average volumetric water content from the soil surface to the maximum depth at a given sampling date

The Darcian flux was estimated as the ratio of the amount of deep percolating water to its duration.

The actual solute velocity, $v$, was estimated from the depth and time it takes the concentration peak to reach the depth (Butters et al., 1989), and the motion of the centre of mass of the solute plume (Ellsworth et al., 1991). The velocity of the concentration peak of the solute can be expressed as:

$$
v_{s}=\frac{\left(z_{p}\right)_{i}-\left(z_{p}\right)_{i-1}}{t_{i}-t_{i-1}}=\frac{\Delta z_{p}}{\Delta t}
$$

and the depth to the centre of mass of the profile as:

$$
\overline{z_{i}}=\frac{1}{m_{i}} \sum_{z=0}^{z=Z} z \theta(z, t) c\left(z, t_{i}\right) A \Delta z
$$

where:

$z_{p}=$ the position of the concentration peak at the sampling time $t_{\text {, }}$

$Z=$ total sample depth and the other symbols have the same meanings defined above.

This yields the following expression for the velocity of the centre of mass of the solute between two sampling times:

$$
v_{s}=\frac{\bar{z}_{1}-\bar{z}_{i-1}}{t_{i}-t_{i-1}}=\frac{D \bar{z}}{D t}
$$

The one-dimensional longitudinal dispersion coefficient can be expressed as (Bear, 1979):

$$
\mathrm{D}=\lambda|v|
$$

where:

$\lambda=$ longitudinal dispersivity and

The solute transport parameters ( $v$ and $D$ ) in these equations were all determined by fitting the observed concentrations at the various depths with the computer package CXTFIT of Toride et al. (1995). This package allows one to fit the observed data to analytical solutions of the conventional convection-dispersion equation(CDE) and the stochastic stream tube model (STM) described by Toride and Leij (1996a and b). The main difference between the CDE and STM is that the CDE model assumes that the concentration of the solute is uniform and perfectly mixed across both the vertical and horizontal planes (Jury and Fluhler, 1992), while the STM considers the field as a series of independent vertical soil columns with no horizontal mixing (Jury and Roth, 1990; Dagan, 1993; Toride and Leij, 1996a).

The CDE and STM in CXTFIT are both continuous source models and therefore do not apply to intermittent sources, such as natural rainfall. However, several authors (Meyer-Windel et al., 1999; Sharma and Taniguchi, 1991; Jury et al., 1982; Wierenga, 1977) have shown that models in CXTFIT can handle intermittent rainfall conditions if cumulative drainage is used as the independent variable instead of time. This approach was therefore also used in this study.
Sampling events

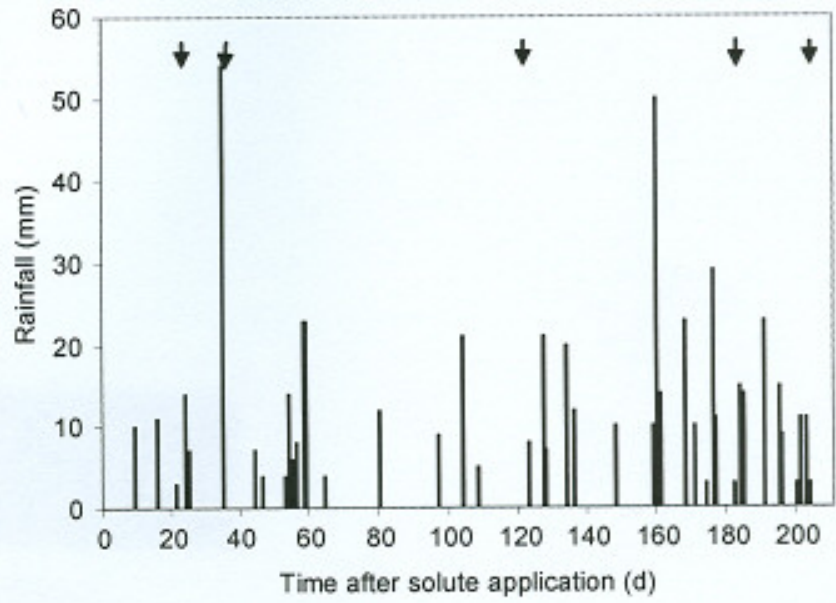

Figure 1

Daily rainfall after the application of bromide and nitrate to the experimental plot

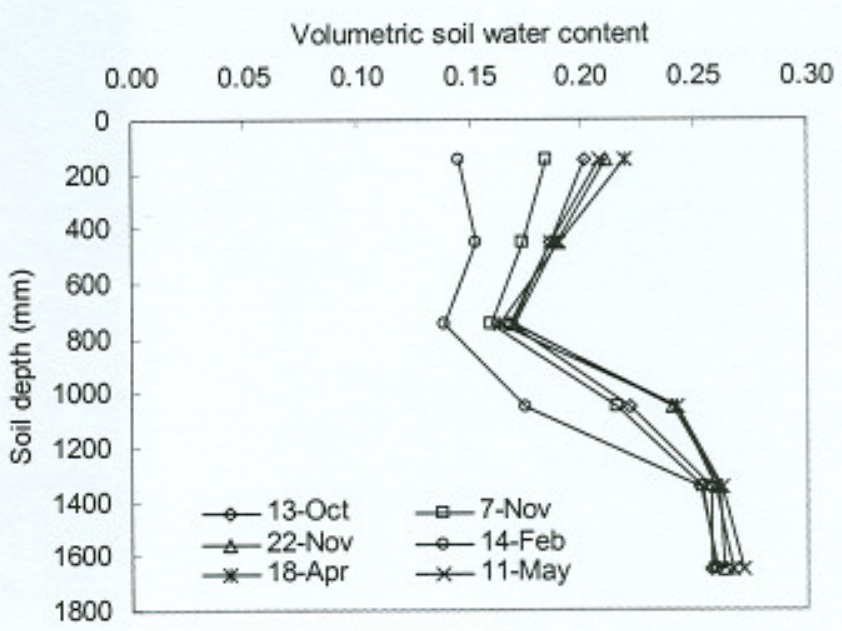

Figure 2

Water content of the soil profile at the dates soil samples were taken

\section{Results and discussion}

\section{Water balance}

Soil sampling times and the daily rainfall during the experimental period are presented in Fig. 1. The total precipitation of $574 \mathrm{~mm}$ from October 2000 to May 2001 was higher than the average of $463 \mathrm{~mm}$ at the experimental site.

As shown in Fig. 2, the average water content in the soil profile decreased from the surface up to a depth of $750 \mathrm{~mm}$ and then increased steadily before it stabilised at depths $\geq 1200 \mathrm{~mm}$. This behaviour seems to be largely determined by the soil bulk density, which reaches a minimum at the same depth as the water content, Table 1, and the clay contents of the soil in Table 1 displays similar behaviour.

Despite high variation in daily rainfall, which varied from $1 \mathrm{~mm}$ for light showers to more than $50 \mathrm{~mm}$ for heavy showers, the 